\title{
Dry cooling with night cool storage to enhance solar power plants performance in extreme conditions areas
}

\author{
J. Muñoz , J.M. Martínez-Val, R. Abbas, A. Abánades
}

\begin{abstract}
A B S T R A C T
Solar thermal power plants are usually installed in locations with high yearly average solar radiation, often deserts. In such conditions, cooling water required for thermodynamic cycles is rarely available. Moreover, when solar radiation is high, ambient temperature is very high as well; this leads to excessive condensation temperature, especially when air-condensers are used, and decreases the plant efficiency. However, temperature variation in deserts is often very high, which drives to relatively low temperatures during the night. This fact can be exploited with the use of a closed cooling system, so that the coolant (water) is chilled during the night and store. Chilled water is then used during peak temperature hours to cool the condenser (dry cooling), thus enhancing power output and efficiency. The present work analyzes the performance improvement achieved by night thermal cool storage, compared to its equivalent air cooled power plant. Dry cooling is proved to be energy-effective for moderately high day-night temperature differences $\left(20^{\circ} \mathrm{C}\right)$, often found in desert locations. The storage volume requirement for different power plant efficiencies has also been studied, resulting on an asymptotic tendency.
\end{abstract}

\section{Introduction}

Solar Thermal Power (STP) requires high solar radiation with a clean and stable atmosphere, i.e. neither humid nor turbulent. This drives to the choice of sunny and arid areas, where STP is mostly installed. However, these locations are characterized as well by water shortage and extremely high temperature during day time, even though they are relatively low during the night. This affects the solar plant performance, as most of them generate electricity via a Rankine cycle $[1,2]$, which implies a strong influence of the condenser temperature, and thus the ambient temperature, on the cycle efficiency (see Fig. 1).

The gross efficiency, $\eta_{G}$, follows the expression:

$\eta_{G}=P_{G} / \dot{Q}_{\mathrm{av}}$

where $P_{G}$ is the electric power output from the generator, and $\dot{Q}_{\mathrm{av}}$ the available thermal power in the solar field. Eq. (1) takes into account the turbine and generator efficiencies, as well as the pumping power consumed by the cycle; however, power required to refrigerate the condenser, i.e. the power consumed by the condenser's pump or fan, is not considered.

The use of water is required if low condenser temperatures are sought. However, it has been already said that water shortages are common in areas where STP plants are installed, and thus the cycle refrigeration design is normally constrained to an air-cooled condenser. As a consequence, its temperature is always notably higher than ambient temperature, which is extremely high during peak radiation hours, decreasing the cycle efficiency when most thermal power is available.

Conventional thermal power plants performance also depends on ambient temperature, the power output and efficiency decreasing during high temperature hours. This power diminution coincides often with peak demand time, mainly due to air conditioning power consumption; this is the case of Saudi Arabia, Iran, India and Thailand, where many studies have been carried out to find the best solution. When power is mainly given by a Gas Turbine (GT), decreasing air inlet temperature to $15^{\circ} \mathrm{C}$ when the ambient temperature is around $40^{\circ} \mathrm{C}$ implies power improvements up to $20 \%$ [4]. This can be achieved by many technologies, such as evaporative cooling, fogging, mechanic chiller, absorption refrigeration and Liquified Natural Gas (LNG) evaporation [4-13]. Nevertheless, evaporative cooling and fogging require water, while LNG evaporation is only useful for GT provided by LNG. Absorption refrigeration could be an interesting way for decreasing STP condenser temperature [14,15], as sun would always be available when the STP were generating electricity; however, it is still not a mature technology, and the absorption cycle would required part of the heat available for refrigerating.

On the other hand, mechanic chillers are able to work during night time, achieving better refrigerating efficiencies thanks to 


\begin{tabular}{|c|c|c|c|}
\hline \multicolumn{4}{|c|}{ Nomenclature } \\
\hline$P_{G}$ & gross power output on a given working mode $(W)$ & $\Delta T_{a-c}$ & difference between the water exiting the air cooler tem- \\
\hline & net power output on a given working mode $(\mathrm{W})$ & & perature and the ambient temperature $\left({ }^{\circ} \mathrm{C}\right)$ \\
\hline$P_{\text {fan }}$ & fan power consumption on a given working mode (W) & $\Delta T_{c}$ & difference between the water exiting the condenser \\
\hline$P_{\text {pump }}$ & $\begin{array}{l}\text { pump power consumption on a given working mode } \\
\text { (W) }\end{array}$ & & $\begin{array}{l}\text { temperature and the condensation temperature }\left({ }^{\circ} \mathrm{C}\right) \\
\text { cooling water specific heat capacity }\left(\mathrm{J} / \mathrm{kg}{ }^{\circ} \mathrm{C}\right)\end{array}$ \\
\hline$\dot{Q}_{\mathrm{av}}$ & available thermal power in the solar field (W) & $\dot{m}_{a}$ & air mass flow in the heat exchanger $(\mathrm{kg} / \mathrm{s})$ \\
\hline$\dot{Q}_{\text {dis }}$ & thermal power to be dissipated at the heat sink (W) & $\dot{m}_{w}$ & cooling water mass flow $(\mathrm{kg} / \mathrm{s})$ \\
\hline$T_{T, c}$ & cold tank temperature $\left({ }^{\circ} \mathrm{C}\right)$ & $t$ & time working on a given working mode (s) \\
\hline$T_{a, \text { day }}$ & day ambient temperature $\left({ }^{\circ} \mathrm{C}\right)$ & $\eta_{G}$ & gross efficiency (\%) \\
\hline$T_{a, \text { night }}$ & night ambient temperature $\left({ }^{\circ} \mathrm{C}\right)$ & $\eta_{\text {daily }}$ & daily average efficiency (\%) \\
\hline & condensation temperature on a given working mode & $d$ & subindex for direct cooling mode \\
\hline & $\left({ }^{\circ} \mathrm{C}\right)$ & $i$ & subindex for indirect cooling mode \\
\hline$\Delta T_{H X}$ & $\begin{array}{l}\text { temperature increase or decrease at each heat exchan- } \\
\text { ger }\left({ }^{\circ} \mathrm{C}\right)\end{array}$ & $s$ & subindex for storage mode \\
\hline
\end{tabular}

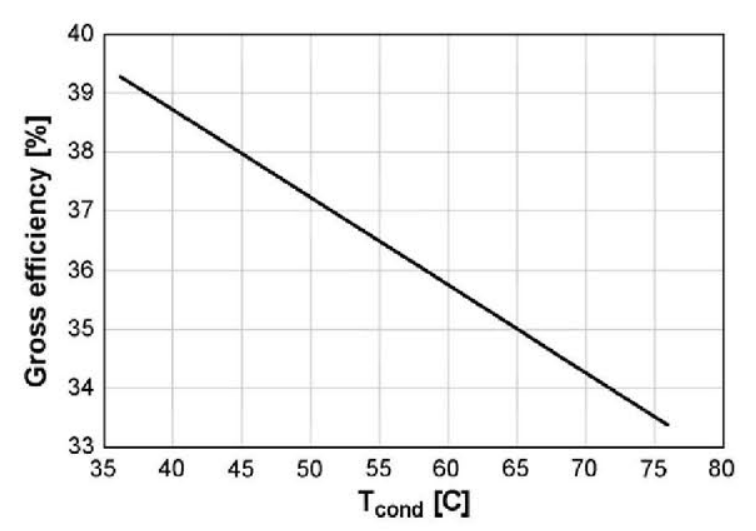

Fig. 1. Rankine cycle performance depending on the condenser temperature, extracted from the model provided by Montes et al. [3].

lower ambient temperatures. This fact is used by some authors to store cold water or ice during cold hours, and use it at peak time either to enhance GT performance, or to cool buildings, shifting air conditioning power demand to off-peak [6,7,9,16-21]. Although ice has a greater specific heat capacity, Ameri et al. [9] recommends the use of chilled water because of high costs associated with the use of ice. In addition, some authors have studied phase change thermal energy storage systems $[22,23]$, which may be used for high and low temperature thermal storage thanks to the wide variety of materials found.

Ambient temperature influence on Combined Cycle Gas Turbine (CCGT) power plants has been extensively studied as well [24-27], concluding that the effect of condensation temperature on plant efficiency is higher than that of inlet air temperature, while the latter has a higher influence on power output. Water is normally available where CCGT plants are built, as their location is not as constrained as for STP plants; thus, evaporative cooling and fogging are useful technologies to decrease air inlet temperature. Another theoretical solution, which has not been put into practice at commercial scale yet, is the use of some of the steam produced in the heat recovery steam generator to feed an absorption refrigeration cycle.

Literature found about temperature influence on Rankine cycles is not as extensive as for GTs and CCGTs. Two methods for improving performance have been studied: Sohel et al. [28] analyze geothermal ORC power plant generation increase by the use of evaporative cooling on the air-condenser already installed, result- ing on an average higher power output of $1 \%$, with peaks up to $6 \%$ on summer. However, this would not be chosen as a first design option, because cooling towers achieve better net efficiencies with similar water availability requirements. Agnew et al. [29] study a Rankine cycle performance when using waste energy in the boiler to feed an absorption cycle to cool condensation temperature, concluding that there is insufficient energy in the flue gases for the absorption cycle used.

Seeking for a solution to this problem, a technology has been suggested for Rankine heat sink cooling when water is not available [30]. Such technology, named dry cooling, is based on the use of a closed water circuit, where the water is chilled during night time and used to refrigerate the condenser during temperature peak hours; this drives to a lower condensation temperature, and thus higher efficiency. The present paper intends to show the plant power increase achievable by the use of this device.

In Section 2 dry cooling system, as well as its different working modes, is presented. For each working mode, the condenser temperature and the net power generated are formulated, obtaining at the end the daily average efficiency. Results from the model are given in Section 3, where the environment and heat exchangers conditions that make the device energy-effective are analyzed, and the storage volume required for each condition is obtained. Finally conclusions are given in Section 4 , where objectives for future works are presented.

\section{The dry-cooling system}

This section is devoted to the understanding of the refrigeration system and the physics standing behind the model. First, the physical system is described, and the specific elements models used to carry out the simulation are indicated. Then, equations representing the physics of the process are explained.

\subsection{System and assumptions description}

The dry-cooling system, depicted in Fig. 2, consists of two tanks - hot and cold water storage respectively -, a water-refrigerated condenser and an air-water heat exchanger. These elements are connected by pumps and valves that allow the system to work on different modes. Such system is ideal for STP located in areas where water availability is limited, and when an important temperature difference between day and night hours characterizes the weather. 


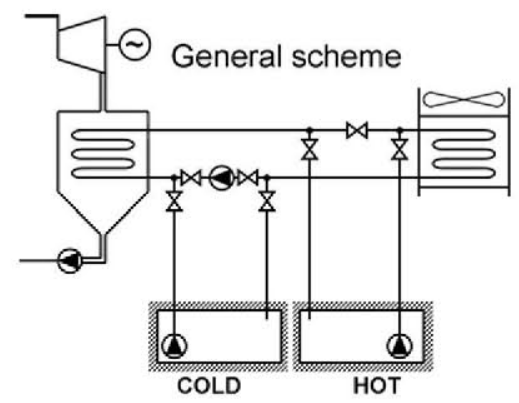

Fig. 2. General scheme of the dry-cooling system suggested, where a cold water and a hot water storage tank, a water-refrigerated condenser an air-water heat exchanger and the tubes, valves and pumps connecting all elements are represented.

\subsubsection{Air cooler}

The Energy Equation Solver (EES) model 'fc-tubes-s80-38T' [31] has been used for simulating the finned circular tubes heat exchanger. This model consists of a set of approximately 12,000 tubes placed in parallel, interconnected by fins perpendicular to them, see Fig. 3.

Air flows within the paths between two consecutive fins, and perpendicular to the tubes where water flows. The overall heat transfer coefficient, as well as the air and water pressure drop, is obtained following the model above, the results depending on the mass flows. The finned circular tubes heat exchanger has been sized so that pressure losses in it are similar to those in the aircondenser used on the reference system. This results on tubes $10 \mathrm{~m}$ long, and an air-cooler $170 \mathrm{~m}$ width and only $10 \mathrm{~cm}$ depth; this enhances the heat transfer and minimizes pressure drop.

\subsubsection{Condenser}

A shell and tubes condenser is used, the cooling water flowing through the tubes, and the steam being condensed within the shell side. The simulation has been carried out admitting a $6 \mathrm{~m}$ length $3 \mathrm{~m}$ wide condenser, with 1800 tubes in it.

\subsubsection{Rankine cycle}

The Rankine cycle considered is based on the turbine model SST-700 previously used in research topics by the authors of this paper [32] and described by Montes et al. [3]. It consists of a $50 \mathrm{MW}$ cycle with six extractions and one intermediate reheat step, the inlet pressure and temperature being 90 bar and $370^{\circ} \mathrm{C}$ respectively.

\subsubsection{Thermal storage}

Thermal storage is carried out in the two tanks depicted in Fig. 2. The tanks are considered adiabatic in the model, due to

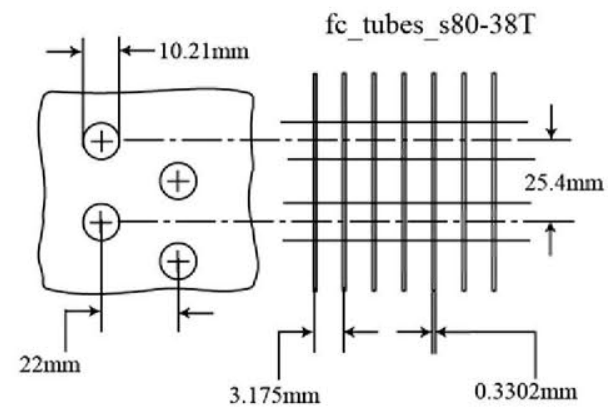

Fig. 3. Air-cooler simulation model from EES data-base - fc-tubes-s80-38T [31] -, where the water flows within the tubes, and the air perpendicular to them, within the paths between two consecutive fins. the fact that temperature differences between any of the tanks and the ground is not very high, the latter being much more stable than the environment temperature. Therefore obtaining quasi adiabatic conditions is not very hard if the tanks are placed under ground and properly isolated. In non-ideal conditions, where there is heat transfer from the tanks to the environment, two antagonist effects take place if the ground temperature is somewhere between the cold and hot tanks temperatures: on the one hand, the cold tank increases its temperature during the day, decreasing power plant efficiency on indirect cooling. On the other hand, the hot tank cools down, requiring therefore less auxiliary power during storage cooling. The correct evaluation of this two effects should be done by a transient study, which is out of the scope of this analysis.

\subsubsection{Other assumptions}

In this paper it has been considered that there are two ambient conditions along $24 \mathrm{~h}$ : day and night. Thermal power is only available during the day, its value being constant. Similarly, the temperature gets a high value during the day, and low during the night, without an intermediate temperature for the early morning or late afternoon. As a result, stationary conditions are always admitted. Finally, water thermo-physical properties are considered constant at all conditions, and pipes are considered adiabatic due to the relatively small temperature difference with the environment.

\subsection{The model}

The dry-cooling system will operate successively in the following modes along the day, depending on the storage availability and the ambient temperature: direct cooling, storage cooling or indirect cooling. Figs. 4-6 show the respective system working modes, where doted lines represent the parts of the circuit that are not in use, being their corresponding pumps off.

\subsubsection{Direct cooling}

This mode (Fig. 4) is used when the power plant is generating electricity, but the ambient temperature is not too high or there is no water left in the cold tank. When the system is operating in this mode, the water passes through the condenser and the aircooler consecutively via a closed loop, and it dissipates at the latter the heat removed from the former.

When working on steady flow, the temperature increase of the cooling fluid at the condenser must be the same as the decrease at the air-cooler. Therefore, the condensation temperature on direct cooling mode, $T_{c_{d}}$, is:

$T_{c_{d}}=T_{a, \text { day }}+\Delta T_{a-c}+\Delta T_{H X}+\Delta T_{c}$

where $T_{a, \text { day }}$ is the ambient temperature during the daytime, $\Delta T_{a-c}$ the difference between the water temperature exiting the air cooler and the ambient temperature, $\Delta T_{H X}$ the water temperature increase

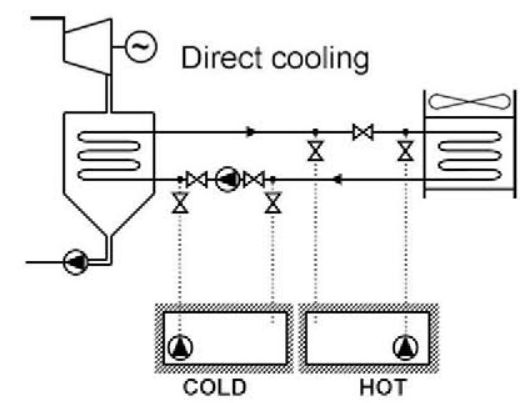

Fig. 4. Direct cooling mode scheme, where the water passes through the condenser and the air-cooler consecutively via a closed loop, the storage tanks not being used. 


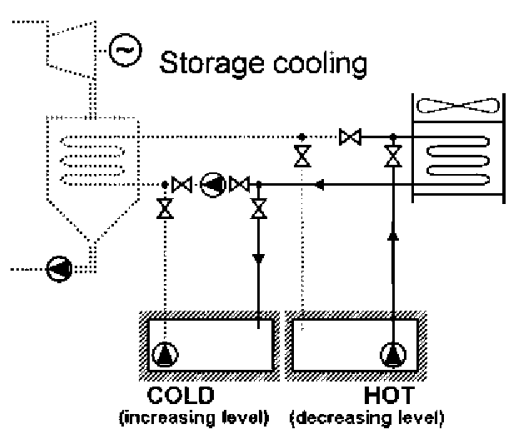

Fig. 5. Storage cooling mode scheme, where the water flows from the hot tank to the cold tank through the water-air heat exchanger, where it is cooled down.

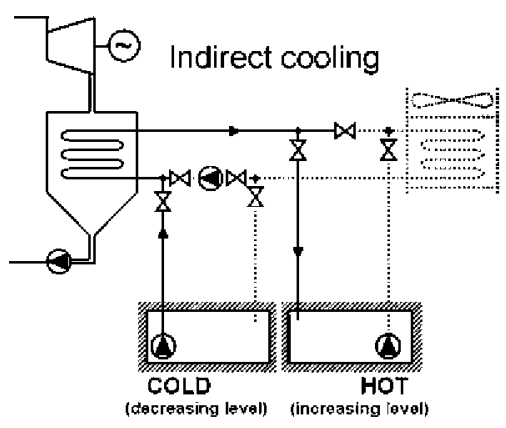

Fig. 6. Indirect cooling mode scheme, where water flows from the cold to the hot tank passing through the condenser, the air-cooler not being used.

or decrease through each heat exchanger and $\Delta T_{c}$ the difference between the refrigerant water temperature exiting the condenser and the condensation temperature.

Auxiliary power consumption in this mode corresponds to the heat exchanger fan and the pump that makes the water flow through the closed loop. Taking into account the foregoing assumptions - steady state and constant variables -, the thermal power to be dissipated at the condenser is constant, and so it is the water mass flow at the condenser:

$\dot{Q}_{\mathrm{dis}_{d}}=\dot{Q}_{\mathrm{av}}-P_{G_{d}}=\dot{Q}_{\mathrm{av}} \cdot\left(1-\eta_{G_{d}}\right)=c_{p} \cdot \dot{m}_{w_{d}} \cdot \Delta T_{H X}$

where $\dot{Q}_{\mathrm{dis}_{d}}$ is the heat power to be dissipated by the system on this mode, $c_{p}$ the cooling water specific heat capacity, and $\dot{m}_{w}$ the water mass flow in the condenser. Similarly, the air mass flow in the airwater heat exchanger, $\dot{m}_{a}$, will be constant, and its value directly proportional to $\dot{Q}_{\text {dis }}$ and inversely proportional its temperature increase in the heat exchanger.

The net power output working on this mode depends on the condensation temperature and the auxiliary power consumption.

$P_{N_{d}}=P_{G_{d}}-P_{\text {pump } d_{d}}-P_{\text {fan }_{d}}$

where $P_{N}$ is the net power output, $P_{G}$ the gross power output (where cycle pump consumption is taken into account), and $P_{\text {pump }}$ and $P_{\text {fan }}$ are respectively the refrigeration system pumps and fans power consumptions in this mode. $P_{G}$ is obtained by introducing the condensation temperature (Eq. (2)) on this mode on the Rankine model, while $P_{\text {pump }}$ and $P_{\mathrm{fan}}$ are given by the model depending on the temperature differences along the circuit, and the heat to be dissipated (Eq. (3)).

Recall that, for a given condenser and heat exchanger geometry, the pressure drop of the air and the water within the circuit is proportional to the square power of its mass flow, and thus the pumping power required is proportional to the cubic power of the same parameter. Therefore, a lower value of $\Delta T_{H X}$ implies, on one hand, that the condenser temperature decreases, and thus $P_{G}$ increases; but on the other hand the mass flows augment, and so does the pumping power.

\subsubsection{Storage cooling}

This mode (Fig. 5) is used during night time, when the STP plant is not generating power due to lack of solar radiation or, considering a wider application, when the power plant is not generating electricity because power demand is low. When the ambient temperature is relatively low, the refrigerant water is carried from the hot to the cold tank through the water-air heat exchanger, where it is cooled down. The water is then stored at relatively low temperatures, and is used for peak time refrigeration when the ambient temperature is very high (indirect cooling).

The cold storage tank temperature is defined as:

$T_{T, c}=T_{a, \text { night }}+\Delta T_{a-c}$

where $T_{a, \text { night }}$ is the ambient temperature during the night.

The auxiliary power used during storage cooling mode, which should be taken into account when estimating the indirect cooling efficiency, corresponds to the use of the fans, $P_{\mathrm{fan}_{\mathrm{s}}}$, and at least one pump, $P_{\text {pump }_{s}}$. It has been seen that the pumping power depends on the mass flow for a given hydraulic circuit. It must be noted that the cooling water volume to pass through the air cooler during the night on storage cooling mode is equal to the volume used on the condenser during the indirect mode, which will be explained later. Thus, their flow mass are related by how many hours the system is working on storage mode, $t_{s}$, and how many on indirect cooling, $t_{i}$ :

$\dot{m}_{w_{s}} \cdot t_{s}=\dot{m}_{i} \cdot t_{i}$

The mass flow on indirect cooling is seen in next paragraph, and so $\dot{m}_{w_{s}}$ may be obtained from Eq. (6). The air flow through the heat exchanger may be obtained is a similar way. As no power is generated in the Rankine cycle, the net power will get a negative value, equal to the pumping power (fans and pumps) corresponding to the mass flows obtained:

$P_{N_{s}}=-P_{\text {pump }_{s}}-P_{\mathrm{fan}_{\mathrm{s}}}$

\subsubsection{Indirect cooling}

This mode (Fig. 6) is used when the power plant is generating electricity, the ambient temperature is close to its daily peak and there is water left in the cold tank to be used as refrigerant. During this working mode, water flows from the cold to the hot tank passing through the condenser, where waste heat is removed. Although the water flows directly from the cold tank to the condenser, it is called indirect mode, as it has been cooled down during the previous night.

The condenser temperature on this mode is therefore:

$T_{c_{i}}=T_{T, c}+\Delta T_{H X}+\Delta T_{C}$

where $T_{T, c}$ is the cold tank temperature, given in Eq. (5). It holds:

$T_{c_{i}}=T_{a, \text { night }}+\Delta T_{a-c}+\Delta T_{H X}+\Delta T_{c}$

Thus the difference between the direct and indirect modes temperature is equal to the day-night temperature difference.

$T_{c_{d}}-T_{c_{i}}=T_{a, \text { day }}-T_{a, \text { night }}$

During this mode the fan is not working, so the only auxiliary consumption corresponds to, at least, one pump. Nevertheless, one should take into account that storage cooling is required at night, which implies an extra consumption. The water mass flows will be given again by heat power dissipated in the refrigeration system, and the temperature augmentation along the condenser: 
$\dot{Q}_{\mathrm{dis}_{i}}=\dot{Q}_{\mathrm{av}}-P_{G_{i}}=\dot{Q}_{\mathrm{av}} \cdot\left(1-\eta_{G_{i}}\right)=c_{p} \cdot \dot{m}_{w_{i}} \cdot \Delta T_{H X}$

Obviously, $\dot{m}_{w_{i}}$ will be very similar to $\dot{m}_{w_{d}}$, but not exactly the same. This is due to the fact that the condenser temperatures are not the same for direct and indirect cooling, and thus the cycle gross efficiency will vary. As a result, the thermal power to be dissipated is higher when the condenser temperature increases, and a higher mass flow is required as well. The net power output, $P_{N_{i}}$, depends takes into account the gross power output given with the condenser temperature, and the pumping power:

$P_{N_{i}}=P_{G_{i}}-P_{\text {pump }_{i}}$

\subsubsection{Daily efficiency}

Integrating the net power output along $24 \mathrm{~h}$, i.e. for the three modes, and dividing by the heat available at the Rankine cycle heat source - the solar field in the case of a STP plant -, the daily average efficiency is obtained:

$\eta_{\text {daily }}=\frac{P_{N_{d}} \cdot t_{d}+P_{N_{s}} \cdot t_{s}+P_{N_{i}} \cdot t_{i}}{\dot{Q}_{a v} \cdot\left(t_{d}+t_{i}\right)}$

\section{Results}

The present work pretends to characterize the cycle efficiency when the following inputs vary:

- Night temperature, $T_{a \text {,night }}$.

- Day-night temperature difference, $\Delta T_{\text {day-night, or day tempera- }}$ ture, $T_{a, \text { day }}$.

- Water temperature increase within a heat exchanger, $\Delta T_{H X}$.

- Daily time of solar radiation, i.e. electricity production period, per day, $t_{d}+t_{i}$.

- Indirect mode hours per day, $t_{i}$.

Obviously, it is not possible to represent the performance of the system when all input values change in one graph. The results will be instead presented in two subsections, the first corresponding to the effect of temperatures, and the second to the effect of the daily time of solar radiation and indirect mode working time per day:

\subsection{Ambient temperatures and heat exchangers temperature difference}

In this subsection solar radiation is fixed to $12 \mathrm{~h}$ per day. This means that storage cooling may be carried out during the remaining $12 \mathrm{~h}$, i.e. during the night. It is considered as well that the system is working $3 \mathrm{~h}$ per day on indirect cooling, and the remaining generation time, $9 \mathrm{~h}$, on direct cooling mode.

Assuming a fixed night temperature of $0{ }^{\circ} \mathrm{C}$, the average daily efficiency decreases as day-night temperature difference increases, as this implies a higher temperature during the day (see Fig. 7). Nevertheless this decrease has a sharper slope for the reference system, i.e. a conventional Rankine cycle using an air cooler. Therefore, there is a given day-night temperature difference from which the system is energy-effective. This point depends on the heat exchangers temperature increase, which gives an idea of the quality of the system. For example, assuming $\Delta T_{H X}$ equal to $30^{\circ} \mathrm{C}$, the dry cooling system achieves a better performance than the reference power plants when day-night temperature difference is higher than $33^{\circ} \mathrm{C}$. For better quality heat exchangers, this value is significantly lower.

It is observed that the dry-cooling system is energy-effective for standard temperature difference in areas close to deserts, such as
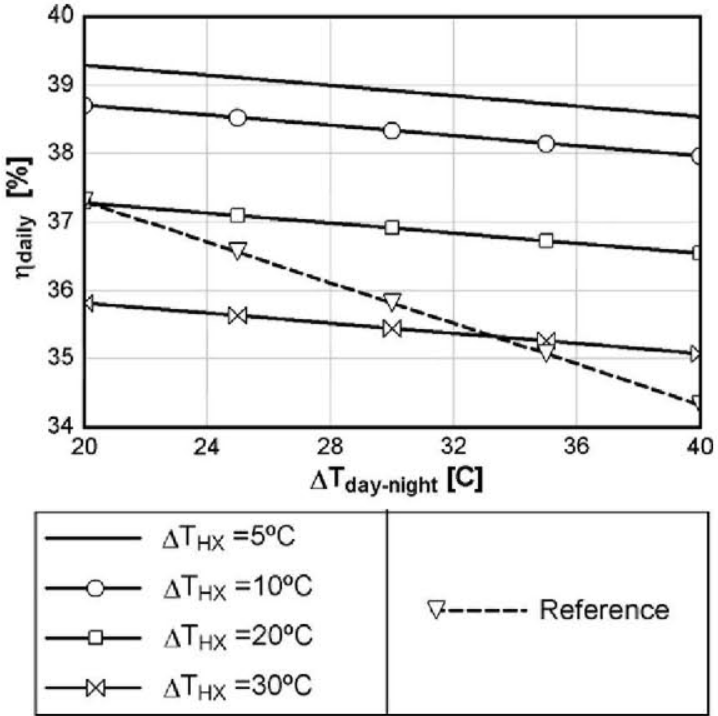

Fig. 7. Daily average efficiency of a STP plant provided of dry cooling system for $12 \mathrm{~h}$ solar radiation, $3 \mathrm{~h}$ indirect cooling and night temperature of $0^{\circ} \mathrm{C}$, depending on the day-night and heat exchangers temperature differences.

Aswan, Egypt, where this difference is approximately $20^{\circ} \mathrm{C}[33]$, or higher as in Atacama Desert [34].

One can observe in Fig. 8 that the slope of the efficiency depending on the heat exchangers temperature difference is nearly independent of the day and night temperatures. The heat exchangers temperature difference has an effect on the efficiency in the sense that it increases the condensation temperature by the value of such difference.

If the STP plant does not have the dry-cooling system, the cycle will be working at the day temperature at all times. Therefore, the efficiency for the hypothetic case of $0{ }^{\circ} \mathrm{C}$ night and $65^{\circ} \mathrm{C}$ day would be much lower than the one of $10^{\circ} \mathrm{C}$ night and $40^{\circ} \mathrm{C}$ day. Nevertheless, thanks to this system the former may achieve a higher net efficiency.

However, the heat exchangers temperature difference is correlated with the tanks volume, see Fig. 9. The volume required and
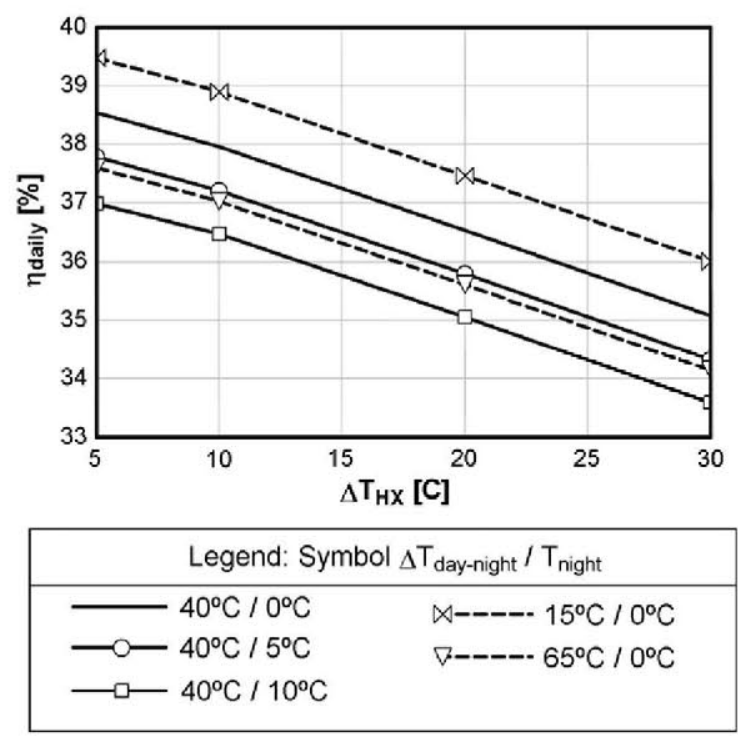

Fig. 8. Daily average efficiency of a STP plant provided of dry cooling system for $12 \mathrm{~h}$ solar radiation and $3 \mathrm{~h}$ indirect cooling, depending on the night temperature and the day-night and heat exchangers temperature differences. 


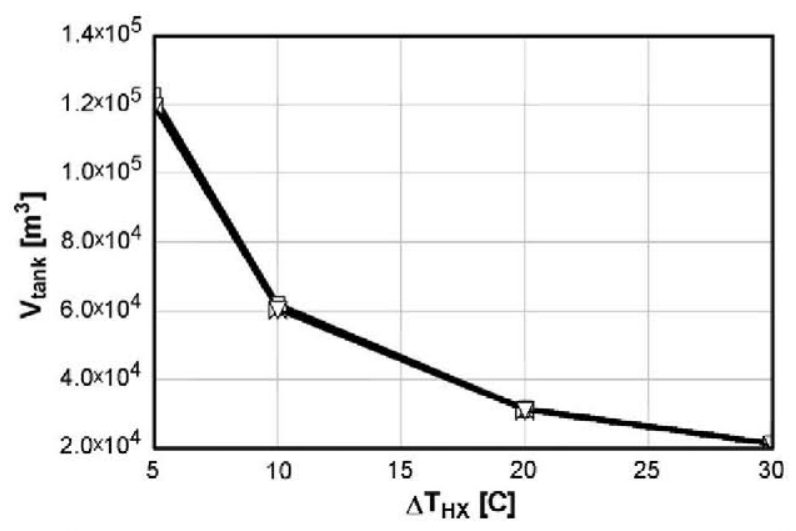

\begin{tabular}{|c|c|}
\hline \multicolumn{2}{|c|}{ Legend: Symbol $\Delta \mathrm{T}_{\text {day-night }} / \mathrm{T}_{\text {night }}$} \\
\hline$-40^{\circ} \mathrm{C} / 0^{\circ} \mathrm{C}$ & $\bowtie----\cdot 15^{\circ} \mathrm{C} / 0^{\circ} \mathrm{C}$ \\
$-40^{\circ} \mathrm{C} / 5^{\circ} \mathrm{C}$ & $\nabla----\cdot 65^{\circ} \mathrm{C} / 0^{\circ} \mathrm{C}$ \\
$-40^{\circ} \mathrm{C} / 10^{\circ} \mathrm{C}$ & \\
\hline- & \\
\hline
\end{tabular}

Fig. 9. Storage volume required for the dry cooling system for $12 \mathrm{~h}$ solar radiation and $3 \mathrm{~h}$ indirect cooling, depending on the night temperature and the day-night and heat exchangers temperature differences.

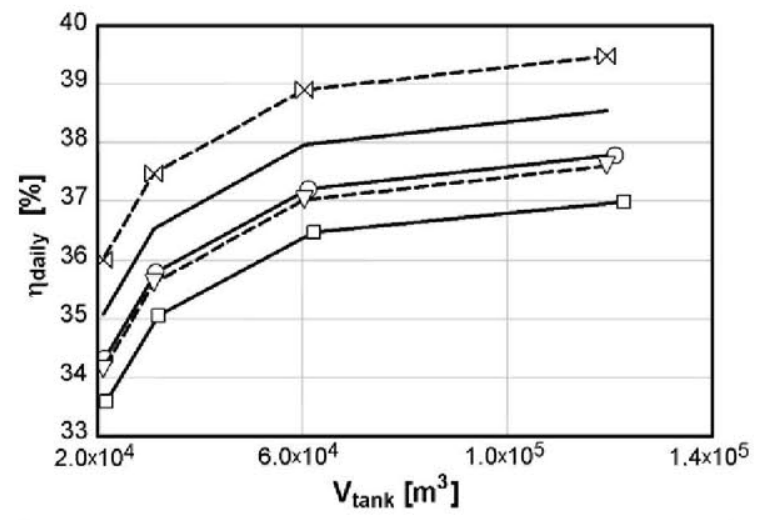

\begin{tabular}{|ll|}
\hline \multicolumn{2}{|c|}{ Legend: Symbol $\Delta T_{\text {day-night }} / \mathrm{T}_{\text {night }}$} \\
\hline$-40^{\circ} \mathrm{C} / 0^{\circ} \mathrm{C}$ & $凶---15^{\circ} \mathrm{C} / 0^{\circ} \mathrm{C}$ \\
$-40^{\circ} \mathrm{C} / 5^{\circ} \mathrm{C}$ & $\nabla---65^{\circ} \mathrm{C} / 0^{\circ} \mathrm{C}$ \\
$-40^{\circ} \mathrm{C} / 10^{\circ} \mathrm{C}$ & \\
\hline- & \\
\hline
\end{tabular}

Fig. 10. Daily average efficiency of a STP plant provided of dry cooling system for $12 \mathrm{~h}$ solar radiation and $3 \mathrm{~h}$ indirect cooling, depending on the night temperature the day-night temperature differences and the storage volume required.

the temperature difference at the heat exchangers do not follow a linear relation, but hyperbolic. This is due to the fact that, for a given time working on indirect mode, the heat dissipated by the water is approximately the same, which must be proportional to the refrigerant volume times its temperature difference (see Eq. (3)).

Figs. 8 and 9 are summarized in Fig. 10, where the correlation between the volume required and the efficiency obtained is depicted. One can observe a saturation effect caused by the previous discussion, so that the efficiency gained per additional storage volume is less important when the tanks become larger. Thus a $\Delta T_{H X}$ value must be chosen where a compromise between system efficiency and tank volume (cost) is obtained, i.e. a heat exchanger temperature difference around the saturation point.

Fig. 9 shows as well that the tank volume required is nearly the same for any day and night temperatures when the $\Delta T_{H X}$ does not change. Water density has been considered constant, due to the fact that temperatures changes would not mean a noticeable difference. Thus, the small volume differences shown are due to differences on dissipated heat, caused by different efficiencies when working on indirect cooling mode, i.e. the highest the night temperature is, the largest the tank must be.

\subsection{Solar radiation and indirect cooling hours per day}

From now on, day and night temperatures are fixed to $40^{\circ} \mathrm{C}$ and $0{ }^{\circ} \mathrm{C}$ respectively, and $\Delta T_{H X}$ to $10^{\circ} \mathrm{C}$ (which is around the saturation area of Fig. 10). Thus the efficiency obtained with dry-cooling depends now on the daily generating time and on the indirect cooling hours per day, see Fig. 11.

The reference efficiency is constant, due to the fact that it always works at day temperature, no matter how many solar radiation hours there are. Power plants provided of dry-cooling system vary their efficiency when daily solar radiation time (generating time) or indirect cooling hours per day change. Even though they appear to have a linear relation with indirect cooling hours, they are actually parabolic, as will be explained later.

If the system is installed but only direct cooling is used, the efficiency is independent of the solar radiation hours per day, and lower than the reference. This is due to the fact that direct cooling is continuously used, the refrigerant water flowing successively in the condenser and the air-cooler. Thus, condenser temperature is higher than in the conventional cycle, as two heat exchangers are used (see Section 2).

On the other hand, indirect cooling efficiency is not independent of how many hours the plant is running on this mode: working temperatures are the same no matter how much indirect cooling is used; however, the water volume to be cooled during night depends on it, and so does the pumping power required to this operation. The fact that the graph seems linear implies that auxiliary power has a limited effect on net power for the condenser and heat exchanger assumed in this simulation.

This fact can be explained looking at Figs. 12 and 13. It has been already said that pressure losses in a hydraulic or pneumatic circuit follow a nearly quadratic relation with the fluid velocity, and
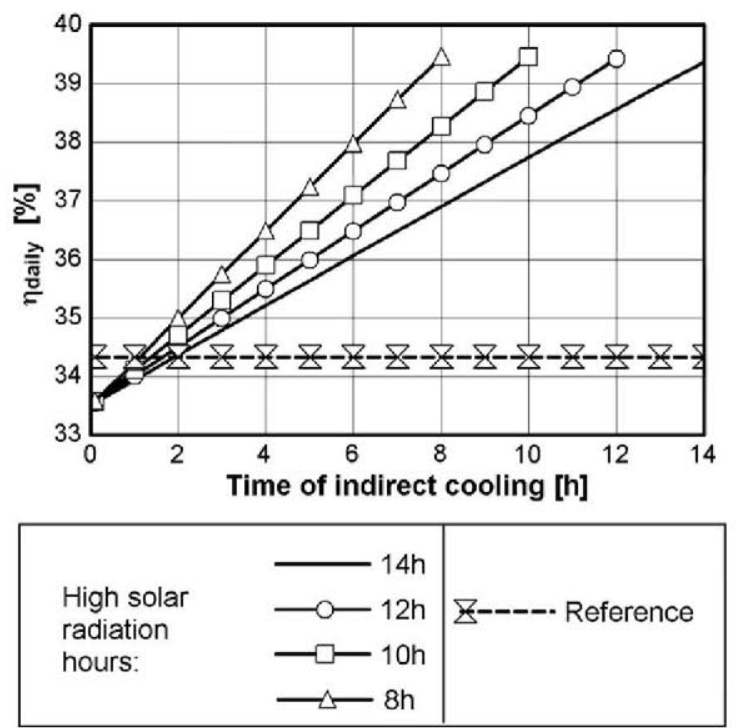

Fig. 11. Daily average efficiency of a STP plant provided of dry cooling system for heat exchangers temperature differences of $10^{\circ} \mathrm{C}$, and day and night temperatures of $40^{\circ} \mathrm{C}$ and $0{ }^{\circ} \mathrm{C}$ respectively, depending on solar radiation time and indirect cooling hours per day. 

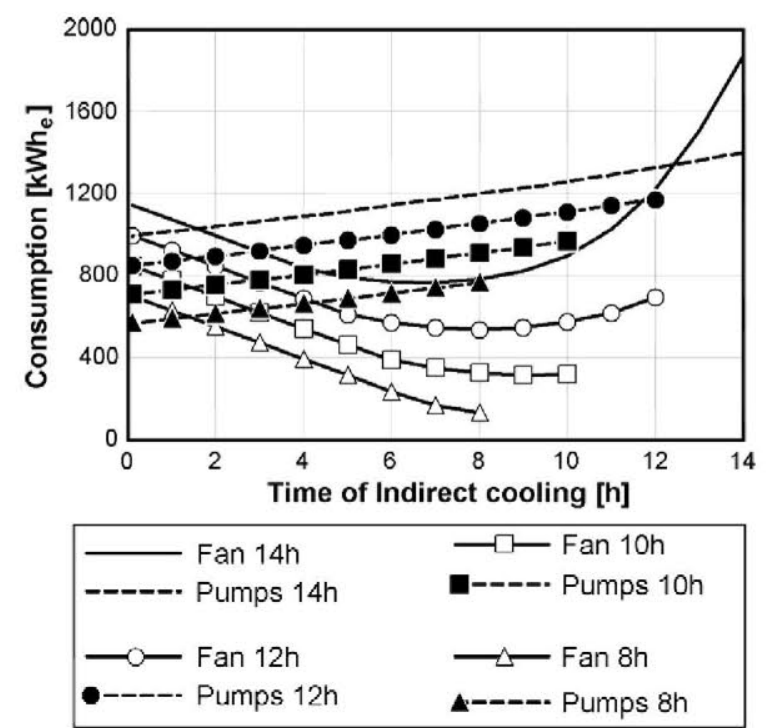

Fig. 12. Fans and pumps power consumptions for heat exchangers temperature differences of $10^{\circ} \mathrm{C}$, and day and night temperatures of $40^{\circ} \mathrm{C}$ and $0^{\circ} \mathrm{C}$ respectively, depending on solar radiation time and indirect cooling hours per day.

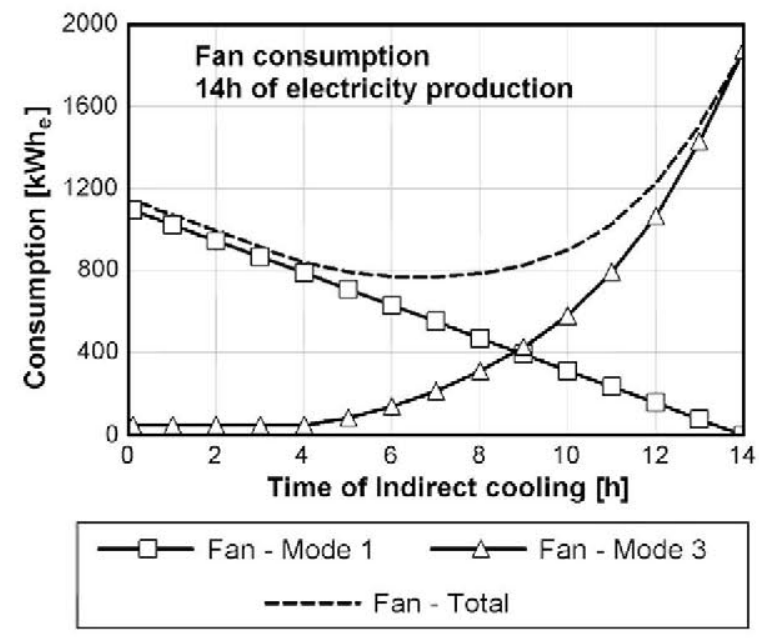

Fig. 13. Electrical consumption of the air-cooler fan split in mode 1 (direct cooling) and mode 3 (storage cooling) for $14 \mathrm{~h}$ of solar radiation.

therefore power consumption of its respective pump or fan is proportional to the cubic power of the fluid mass flow.

The fans are working on direct and storage cooling modes only, as on indirect cooling refrigerant water flows directly from the cold to the hot tank. As explained before, fan consumption on direct cooling mode is always the same, but this is not the case for storage cooling. The time to cool the cold tank is always the same $(24 \mathrm{~h}$ minus solar radiation hours), but the volume to be displaced, assuming the same $\Delta T_{H X}$, is proportional to the time using indirect cooling. Thus, the mass flow that the fan pumps is proportional to the time working on indirect cooling, and the power (and so energy) required for this mode follows a cubic power of such time. This is the reason why one can observe a minimum consumption point on Fig. 13.

Additionally, indirect cooling implies that the cooling water has to flow twice through the circuit, and thus consumption due to water pumping power is higher. Nevertheless, the indirect cooling hydraulic circuit produces a lower pressure drop than direct cooling, the consumption slope not being very stiff. It is remarkable
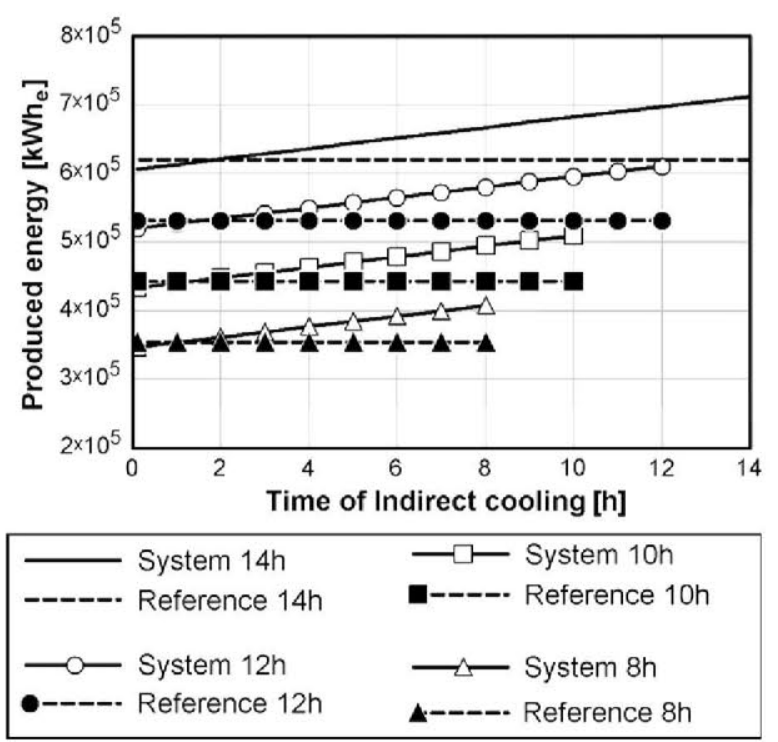

Fig. 14. Produced energy for heat exchangers temperature difference of $10^{\circ} \mathrm{C}$, and day and night temperatures of $40^{\circ} \mathrm{C}$ and $0^{\circ} \mathrm{C}$ respectively, depending on solar radiation time and indirect cooling hours per day.

that pumps power consumption on storage cooling mode follows a cubic power relation with the time used on indirect mode as well, but, the pressure losses being lower, this effect is not as explicit as for the fans.

Obviously, the maximum efficiency is not found where the minimum auxiliary power consumption is. The aim of the dry-cooling system is not to reduce auxiliary consumption, but to improve the Rankine cycle efficiency by reducing the heat sink temperature. If the system is working more time on indirect cooling, more power is produced (Fig. 14), achieving a better net efficiency (Fig. 11) despite auxiliary consumption increase (Fig. 13).

\section{Conclusions and future works}

The application to thermal power plants of a dry-cooling system with cool thermal storage has been studied. This system aims to increase the daily average efficiency of Rankine cycle based power plants mainly used during day time, and located in areas where water is not available and where an important temperature difference between day and night time is found. This is often the case the solar power plants, which are normally installed in deserts due to the necessity of high solar radiation along the year.

It has been found that decreasing condensation temperature by $7^{\circ} \mathrm{C}$ increases the cycle efficiency by 1 percentage point (Fig. 1). Nevertheless, very few papers have been published on how to achieve such a temperature decrease on the heat sink of a Rankine cycle, and their proposals normally imply water consumption. Other papers aim to mitigate temperature effects on gas turbines performance by reducing the air temperature at compressor's inlet; some of these papers suggest storage of ice or cold water chilled via mechanical chillers during the night for a better coefficient of performance (COP). However, to the authors knowledge, no paper has been published where a system takes advantage of day-night temperature difference to enhance peak-time efficiency by directly transferring the fluid heat to the environment during the night $[6,18-21]$.

The analysis carried out shows an important net efficiency improvement compared to the reference power plant, that uses an air condenser (Fig. 8). The higher the day-night temperature difference, the more energy-effective the dry cooling system, 
achieving important efficiency improvements for temperature differences around $20^{\circ} \mathrm{C}$.

Efficiency gain does not only depend on the ambient conditions, but also on the heat exchangers temperature difference: when the latter is lower, condensation temperature decreases both on direct and indirect cooling modes, and therefore the efficiency is enhanced. Nevertheless, lower heat exchangers temperature difference implies larger storage tanks, so higher costs. It seems to appear a saturation of the efficiency when the storage volume is increased, i.e. when the water temperature change through a heat exchanger is decreased (Fig. 11); this saturation is found at around $10{ }^{\circ} \mathrm{C}$ for the system and conditions considered.

The results obtained show that a solar thermal power plant may achieve an efficiency increases of around six percentage points by the use of dry cooling during the whole day. In addition, such system implies the consumption of electricity during the night, when prices are lower, to increase power generation on peak hours; this would make the dry-cooling more cost-effective. However, the economic analysis of the system is out of the scope of the present work.

The main simplification assumed for this study is that the temperature profile along $24 \mathrm{~h}$ consists in two plateaus: one at high temperature that simulates the day hours, and the other at lower temperature for night time. Future works could take into account a more accurate temperature profile that would surely imply a reduction of indirect cooling working time for an optimized system. In addition, this system can be applied as well to fossil fuel thermal power plants installed in desert areas, that may work partially or totally during the night. Future works will analyze the suitability of dry cooling for such power plants. Finally, an exergoeconomic analysis of the system should be carried out to take into account the antagonist influence of the heat exchangers size on both the pumping power and the cost of the cooling system.

\section{References}

[1] Duffie J, Beckman W. Solar engineering of thermal processes. 2nd ed. John Wiley And Sons; 1991. ISBN: 0-471-51056-4

[2] Kalogirou S. Solar energy engineering: processes and systems. Academic Press; 2009. ISBN: 0-123-74501-2.

[3] Montes M, Abánades A, Martínez-Val J, ValdTs M. Solar multiple optimization for a solar-only thermal power plant, using oil as heat transfer fluid in the parabolic trough collectors. Sol Energy 2009;83(12):2165-76. ISSN: 0038$092 \mathrm{X}$.

[4] Kakaras E, Doukelis A, Karellas S. Compressor intake-air cooling in gas turbine plants. Energy 2004;29(12-15):2347-58. ISSN: 0360-5442.

[5] Mohanty B, Paloso G, et al. Enhancing gas turbine performance by intake air cooling using an absorption chiller. Heat Recovery Syst CHP 1995;15(1):41-50. ISSN: 0890-4332.

[6] Hasnain S. Review on sustainable thermal energy storage technologies. Part II: cool thermal storage. Energy Convers Manage 1998;39(11):1139-54. ISSN: 0196-8904.

17] Hasnain S, Alawaji S, Al-Ibrahim A, Smiai M. Prospects of cool thermal storage utilization in Saudi Arabia. Energy Convers Manage 2000;41(17):1829-39. ISSN: 0196-8904

[8] Ameri M, Hejazi S. The study of capacity enhancement of the Chabahar gas turbine installation using an absorption chiller. Appl Therm Eng 2004;24(1):59-68. ISSN: 1359-4311.

[9] Ameri M, Hejazi S, Montaser K. Performance and economic of the thermal energy storage systems to enhance the peaking capacity of the gas turbines. Appl Therm Eng 2005;25(2-3):241-51. ISSN: 1359-4311.
10] Dawoud B, Zurigat Y, Bortmany J. Thermodynamic assessment of power requirements and impact of different gas-turbine inlet air cooling techniques at two different locations in Oman. Appl Therm Eng 2005;25(11-12):1579-98. ISSN: $1359-4311$.

11] Hisazumi Y. The development of the hybrid vaporization and powe generation system for gas turbine using LNG cold. Nippon Kikai Gakka Kansai Shibu Teiji Sokai Koenkai Koen Ronbunshu 2005;80:1-23.

12] Behafarid $F$, Bahadori $M$. Performance evaluation of a gas turbine operating noncontinuously with its inlet air cooled through an aquifer thermal energy storage. J Energy Resour Technol 2007;129:117.

[13] Al-Ibrahim A, Varnham A. A review of inlet air-cooling technologies for enhancing the performance of combustion turbines in Saudi Arabia. Appl Therm Eng 2010;30(14-15):1879-88. ISSN: 1359-4311.

[14] Meng X, Yang F, Bao Z, Deng J, Serge NN, Zhang Z. Theoretical study of a nove] solar trigeneration system based on metal hydrides. Appl Energy 2010;87(6):2050-61. ISSN: 0306-2619.

[15] Mokhtar M, Ali MT, BrSuniger S, Afshari A, Sgouridis S, Armstrong P, et al. Systematic comprehensive techno-economic assessment of solar cooling technologies using location-specific climate data. Appl Energy 2010;87(12):3766-78. ISSN: 0306-2619.

[16] Asrael J, Phelan P, Wood B. Feasibility of lowering the condenser's inlet water temperature of a chiller using thermal water storage. Appl Energy 2000;66(4):339-56. ISSN: 0306-2619.

[17] Alawadhi E. Numerical analysis of a cool-thermal storage system with a thermal conductivity enhancer operating under a freezing condition. Energy 2008;33(5):796-803. ISSN: 0360-5442.

[18] Hasnain S. Review on sustainable thermal energy storage technologies. Part I: heat storage materials and techniques. Energy Convers Manage 1998:39(11):1127-38. ISSN: 0196-8904.

[19] Gil A, Medrano M, Martorell I, Lázaro A, Dolado P, Zalba B, et al. State of the art on high temperature thermal energy storage for power generation. Part 1 concepts, materials and modellization. Renew Sustainable Energy Rev 2010;14(1):31-55. ISSN: 1364-0321.

[20] Medrano M, Gil A, Martorell I, Potau X, Cabeza L. State of the art on hightemperature thermal energy storage for power generation. Part 2 - case studies. Renew Sustainable Energy Rev 2010;14(1):56-72. ISSN: 1364-0321.

[21] Mccann N. Cooling system for building air supply, Patent WO/2009/089618; 2009

[22] Tay N, Belusko M, Bruno F. Experimental investigation of tubes in a phase change thermal energy storage system. Appl Energy, ISSN 0306-2619.

[23] Tao Y, He Y. Numerical study on thermal energy storage performance of phase change material under non-steady-state inlet boundary. Appl Energy 2011;88(11):4172-9. ISSN: 0306-2619.

[24] Valdés M, Rovira A, Fernández J. The influence of atmospheric conditions on the performance of combined cycle gas turbine power plants. ASME Turbo Expo; 2006

25] Boonnasa S, Namprakai P. Sensitivity analysis for the capacity improvement of a combined cycle power plant (100-600 MW). Appl Therm Eng 2008;28(1415):1865-74. ISSN: $1359-4311$.

[26] Kim TS, Ro ST. Power augmentation of combined cycle power plants using cold energy of liquefied natural gas. Energy 2000;25(9):841-56. ISSN: 0360-5442.

[27] Yang C, Yang Z, Cai R. Analytical method for evaluation of gas turbine inlet air cooling in combined cycle power plant. Appl Energy 2009;86(6):848-56. ISSN 0306-2619.

[28] Sohel MI, Sellier M, Brackney L], Krumdieck S. Efficiency improvement for geothermal power generation to meet summer peak demand. Energy Policy 2009;37(9):3370-6. ISSN: 0301-4215, new Zealand Energy Strategy.

[29] Agnew B, Alaktiwi A, Anderson A, Potts l. Simulation of a combined Rankineabsorption cycle. Appl Therm Eng 2004;24(10):1501-11. ISSN: 1359-4311.

[30] Martínez-Val J, Valdés $M$, Abánades A, Amengual R, Piera M, Montes $M$, et al. Cooling system for thermal power stations, Patent Wo/2010/142,820; 2010.

[31] F-chart. EES: engineering equation solver; 2011. <www.fchart.com/ees/>

[32] Muñoz J, Abánades A, Martínez-Val J. A conceptual design of solar boiler. Sol Energy $2009 ; 83(9): 1713-22$. ISSN: 0038-092X

[33] S.U. of Wisconsin. TRNSYS 16 - a transient systems simulation program; 2005 $<$ http://sel.me.wisc.edu/>

[34] Mackay C, Friedmann E, Gomez-Silva B, Caceres-Villanueva L, Andersen D Landheim R. Temperature and moisture conditions for life in the extreme arid region of the atacama desert: four years of observations including the El Niño of 1997-1998. Astrobiology 2003;3(2):393-406. ISSN: 1531-1074. 